\title{
HIV care cascade in Albania: analysis of newly diagnosed cases in 2016
}

\author{
Arjan Harxhi' ${ }^{1,2}$, Enxhi Vrapi ${ }^{2}$, Arsilda Gjataj ${ }^{2}$, Esmeralda Meta ${ }^{2}$, Artan Simaku ${ }^{3}$, Roland Bani ${ }^{4}$, \\ Deniz Gokengin ${ }^{5}$, Colette Smith ${ }^{6}$, Mike Youle ${ }^{6}$ \\ ${ }^{1}$ Department and Service of Infectious Diseases, Faculty of Medicine, University Hospital Center, Tirana, Albania \\ ${ }^{2}$ Department of Infectious Diseases, Faculty of Medicine, Tirana, Albania \\ ${ }^{3}$ Institute of Public Health, Albania \\ ${ }^{4}$ Institute of Public Health, National HIV Program, Tirana, Albania \\ ${ }^{5}$ Department of Infectious Diseases and Clinical Microbiology, Faculty of Medicine, Ege University Izmir, Turkey \\ ${ }^{6}$ Royal Free Hospital, United Kingdom
}

\begin{abstract}
Introduction: Despite the fact that there has been a steady rise in new infections rate since the first reported case in 1993, Albania remains a low prevalence country. This was the first cascade study for Albania. The aim was to construct a cascade of care for newly human immunodeficiency virus (HIV)-diagnosed individuals in 2016 in Albania.

Material and methods: This retrospective descriptive study was conducted at the HIV/AIDS Ambulatory Clinic, Infectious Disease Service, University Hospital Centre of Tirana. Medical records of patients diagnosed and enrolled in care in 2016 were retrospectively screened and data on gender, age, HIV clinical stage, CD4+ T cell count, viral load measurement, and treatment history, with antiretroviral treatment (ART) and adherence to treatment were collected.

Results: Out of 127 new HIV cases reported, 100 (78.7\%) entered care. The median age was 39 years (range, 20-75 years; male, 82\%). Seventy one percent started ART within a median of 56 days (range, 1-317 days) from diagnosis, 34 (47.9\%) patients received tenofovir disoproxil fumarate/emtricitabine + efavirenz (EFV), and 27 (38\%) zidovudine + lamivudine + EFV. Among those who started ART, 19.7\% were late presenters and $54.9 \%$ were very late presenters. Viral load after initiation of ART was assessed in 25 cases, with $56 \%$ of patients achieving an undetectable HIV-RNA.

Conclusions: A large proportion of people living with HIV were lost at each step of the cascade. Efforts in Albania should be focused on scaling up HIV testing, promoting adherence to ART, improving access to diagnostics, and better ART regimens as well as proper monitoring of therapy.

Key words: cascade of care, antiretroviral treatment, late presentation.

\section{Introduction}

Since its emergence in the summer of 1981, human immunodeficiency virus (HIV)/acquired immunodeficiency syndrome (AIDS) has proven to be a major global public health

Address for correspondence: Artan Simaku, Institute of Public Health, Albania, e-mail: artan.simaku@gmail.com

problem [1]. In 2017, the estimated number of people living with HIV (PLWH) was reported as 36.9 million [2]. The fight against HIV has been ongoing, initially concentrating on identifying the causative agent and then, focusing on controlling the epidemic. The first antiretroviral (ARV) drug,

Article history:

Received: 02.12.2019

Received in revised form: 18.03 .2020

Accepted: 20.08.2020

Available online: 30.11 .2020
International Journal of HIV-Related Problems

HIV \& AIDS

R e v i e w 
zidovudine (AZT), was introduced in 1987 and since then, a wide range of ARVs have been developed, with over time increased potency and reduced toxicity. Since a treatment reduces onward transmission and reverses immune suppression, there has been a decline in new infections and HIVrelated deaths within the last decade. Therefore, the UNAIDS proposed an ambitious international target known as the "90-90-90 target", aiming to diagnose $90 \%$ of those living with HIV, initiating ART in $90 \%$ of diagnosed individuals ( $81 \%$ of all people with HIV), and achieving virologic suppression in $90 \%$ of those on ART (73\% of all those living with HIV) by 2020 , with an ultimate goal to significantly reduce the HIV epidemic by 2030 [3]. Successful viral suppression is associated with sequential key steps in HIV care, comprising diagnosis, linkage to care, retention in care, and adherence to treatment [4]. The representation of these stages as a continuous cascade helps to identify the strengths and weaknesses of HIV care for different countries and subgroups of population [5]. This model is now globally used to quantify the HIV epidemic worldwide, in consistent HIV care system and proper functioning of every step of the cascade, which is crucial for achieving the goal. Differences are to be expected between countries, where diagnosis, treatment, and care approaches reflects in respective treatment cascades [6].

The Albanian National Program for Prevention and Control of HIV/AIDS was established in August 1987 in the Ministry of Health, with direct support of the World Health Organization (WHO). It aimed to understand, control, and prevent HIV infection, and was later remodeled by including multidisciplinary team of doctors and epidemiologists affiliated with the Institute of Public Health (IPH) [7]. In the initial surveillance system, all reported cases in Albania were registered in the HIV National Program. From the first confirmed case in 1993, there has been a steady rise in new infections until 2016, with a cumulative number of $1,009 \mathrm{HIV}$ infections (723 male and 286 female). Albania remains a low prevalence country and the National Strategy of HIV Prevention aims at maintaining this rate $[7,8]$. An ambulatory HIV clinic at the University Hospital Center of Tirana (UHCT) is the only national treatment and care center for adult HIV patients ( $>15$ years old) [7]. All HIV cases are confirmed by a central laboratory with ELISA and western blot tests, and reported in the HIV National Reporting Center at the National Institute of Public Health.

This article summarizes the steps of care of people living with HIV, from initial diagnosis to achieving viral suppression, and constructs a detailed cascade of care for newly HIV-diagnosed individuals in 2016. This was the first cascade of care study performed in Albania.

\section{Material and methods}

This was a retrospective, descriptive cohort study conducted at the HIV Clinic of UHCT and the National Institute of Public Health National HIV Program.
Information on undiagnosed HIV population in Albania was not available, therefore HIV-diagnosed population was applied as a denominator for continuum of care. All people diagnosed with HIV in Albania in 2016 constituted this denominator. Of 127 reported HIV diagnoses in 2016, 100 patients were registered and followed up at the clinic. For each patient, data from clinical records were obtained, including gender, age, HIV clinical diagnosis, CD4+ T cell count, viral load measurement, and treatment history, with a reference to ART access and adherence to treatment. Stages of the disease were defined according to the recent CDC classification [9]. Status of the patients was classified as per the British HIV Association consensus, with late presenters defined as cases with a CD4+ T cell count $<350$ cells/ $\mu$ l and/or with symptomatic disease, and very late presenters specified as those with a CD4+ T cell count $<200$ cells/ $\mu$ l [10]. Full retention in care was defined as two clinic visits during a calendar year, at least 2-6 months apart. Antiretroviral treatment coverage was assessed as a percentage of those diagnosed, who were currently receiving ARV treatment on $31^{\text {st }}$ December 2016 [11], and viral suppression was defined as an HIV RNA < 50 copies $/ \mathrm{ml}$. A reported adherence of more than $95 \%$ was defined as good adherence to antiretroviral therapy, based on patient reporting the number of missed doses in the last month.

\section{Statistical analysis}

Kolmogorov-Smirnov test was used to evaluate the distribution of continuous variables. Categorical variables were presented as absolute frequencies and percentages. $\chi^{2}$ test was applied to compare the proportions between categorical variables. Descriptive statistics of continuous variables were summarized as median and range. Data was analyzed using statistical package for the social sciences (SPSS) version 20. All statistical evaluations were two-sided tests.

\section{Results}

In 2016, there were 127 new HIV diagnoses in Albania, of which 100 (78.7\%) entered care at the clinic. There was no information on those who were not linked to care. The median age was 39 years (range, $20-75$ years), with $82 \%$ of males and $18 \%$ of females. Twelve (12\%) patients were infected with HIV during sex between men (MSM). Half (50\%) of the individuals were residing and diagnosed in Tirana. The majority $(67 \%)$ of the cases were diagnosed at a hospital, with only 13 (13\%) patients diagnosed through voluntary testing. Voluntary testing was significantly more frequent among MSM compared to other groups $(p<0.01)$. The characteristics of newly diagnosed cases are shown in Table 1 .

In the present study, the median time from diagnosis to enrollment in care (registered at HIV clinic) was 19 days (range, 0-317 days). Overall, 75 out of 100 patients (75\%) were enrolled in care within two weeks of diagnosis, and 86 patients $(86 \%)$ accessed a treatment within the first month. Data for CD4+ T cell counts was available for 98 patients and 
was measured within two weeks of diagnosis in 44 (44.9\%) cases, and in the first month in 52 (53.1\%) individuals (Table 1). In total, 67 (67\%) patients were diagnosed late and $49(49 \%)$ cases with advanced disease. Out of the 100 patients, $66(66 \%)$ had an AIDS diagnosis, with a CD4+ T cell count $<200$ cells/ $\mu$ ( 49 patients) and/or with an AIDS defining clinical condition. ART was initiated in 71 patients (71\%); the most common ART regimens included tenofovir (TDF)/emtricitabine (FTC) + efavirenz (EFV) in 34 (47.9\%) patients, and zidovudine (AZT) + lamivudine (3TC) + EFV in $27(38 \%)$ patients (Table 2). Only 4 (5.6\%) patients, which started using ART, had a CD4+ T cell count $>500$ cells/ $\mu$ l. Fourteen (19.7\%) patients on ART were late presenters and $39(54.9 \%)$ cases were very late presenters. Thus, ART was initiated in $47.8 \%(32 / 67)$ of late presenters and $79.6 \%$ $(39 / 49)$ of very late presenters, with statistically significant difference of $p<0.01$. Fifty-seven patients (80.3\%) reported taking the medications regularly, whereas 14 (19.7\%) patients were non-adherent to their regimens. The median time from diagnosis to the initiation of treatment was 56 days (range, $1-317$, days); $36 \%$ started ARV within two weeks of diagnosis and $58 \%$ within the first month.

Ten (10\%) deaths were reported among the patients diagnosed and enrolled in care during the study, all classified as very late presenters; 7 patients were at stage C3 AIDS and 3 were stage B3 AIDS. CD $4+$ T cell count was $<50$ cells $/ \mu$ in 9 cases and $<100$ cells $/ \mu$ in one patient. Only five patients had taken ART, while for the rest, ART initiation was not possible due to very rapid fatal course of the disease. Death occurred within a median of 70 days (range, 7- 208 days) from HIV diagnosis and 46 days from the initiation of the therapy.

Of the 100 patients enrolled in care, a baseline viral load measurement was performed in only 58 patients (58\%), with a median time of 83 days (range, 0-317 days) from the confirmation of the HIV positive status. In the remaining 42 patients, only an immunological assessment (CD4+ T cell counts) was performed.

In 25 (35.2\%) out of 71 cases receiving ART at least one viral load measurement was performed after the initiation of therapy within a median of 143.8 days (range, 26-340 days). Suppression to $<50$ copies $/ \mathrm{ml}$ was achieved in only $14(56 \%)$ out of 25 individuals, at a median of 184 days after commencing ART (range, 43-340 days). During follow-up, $\mathrm{CD} 4+\mathrm{T}$ cell counts were available for 16 cases, of whom 7 had an additional viral load monitoring. Therefore, in 9 patients, CD4+ T cell counts were the only surrogate marker of prognosis and response to the treatment. The cascade of care is presented in Table 3.

\section{Discussion}

The aim of this study was to analyze the HIV cascade of care for newly HIV-diagnosed adults in Albania in 2016. A total of 127 new HIV diagnoses were confirmed and reported during 2016, representing the highest incidence of new cases seen yet. A study conducted in 2015 document-
Table 1. Characteristics of individuals newly diagnosed with HIV and engaged in care in 2016

\begin{tabular}{l|c|c|c}
\hline Characteristics & $\begin{array}{c}\text { Total } \\
N(\%)\end{array}$ & $\begin{array}{c}\text { Started } \\
\text { ART, } \\
n(\%)\end{array}$ & $\begin{array}{c}\text { Did not } \\
\text { start ART, } \\
n(\%)\end{array}$ \\
\hline Total & $100(100.0)$ & 71 & 29 \\
\hline
\end{tabular}

Gender

\begin{tabular}{l|c|c|c}
\hline Male & $82(82.0)$ & 60 & 22 \\
\hline Female & $18(18.0)$ & 11 & 7 \\
\hline
\end{tabular}

\begin{tabular}{|c|c|c|c|}
\hline \multicolumn{4}{|l|}{ Age, years } \\
\hline $18-24$ & $16(16.0)$ & - & - \\
\hline $25-34$ & $27(27.0)$ & - & - \\
\hline $35-44$ & $24(24.0)$ & - & - \\
\hline $45-54$ & $20(20.0)$ & - & - \\
\hline $55-64$ & $12(12.0)$ & - & - \\
\hline$\geq 65$ & $1(1.0)$ & - & - \\
\hline \multicolumn{4}{|l|}{ Transmission route } \\
\hline MSM & $12(12.0)$ & - & - \\
\hline \multicolumn{4}{|l|}{ Mode of diagnosis } \\
\hline $\begin{array}{l}\text { Inpatient/ } \\
\text { outpatients } \\
\text { hospital setting }\end{array}$ & $67(67.0)$ & - & - \\
\hline $\begin{array}{l}\text { Voluntary and } \\
\text { confidential } \\
\text { testing (VCT) }\end{array}$ & $13(13.0)$ & - & - \\
\hline Transfusion centers & $16(16.0)$ & - & - \\
\hline $\begin{array}{l}\text { Follow-up } \\
\text { undetermined }\end{array}$ & $4(4.0)$ & - & - \\
\hline $\begin{array}{l}\text { Time from diagnosis } \\
\text { to enrollment in } \\
\text { care (days) }\end{array}$ & $19(0-317)$ & - & - \\
\hline
\end{tabular}

First CD4+ count (cells $/ \mu \mathrm{L}), n=98$

\begin{tabular}{l|c|c|c}
\hline$>500$ & $13(13.3)$ & 4 & 9 \\
\hline $350-499$ & $18(18.4)$ & - & - \\
\hline $200-350$ & $18(18.4)$ & - & - \\
\hline $100-199$ & $14(14.3)$ & - & - \\
\hline $50-100$ & $10(10.2)$ & - & - \\
\hline$<50$ & $25(25.5)$ & - & - \\
\hline Late presenter & $67(67.0)$ & $32(47.8)$ & - \\
\hline Very late presenter & $49(49.0)$ & $39(54.9)$ & - \\
\hline
\end{tabular}

Time from diagnosis to CD4+ count

\begin{tabular}{l|c|c|c}
\hline$<1$ week & $26(26.5)$ & - & - \\
\hline $1-2$ weeks & $18(18.4)$ & - & - \\
\hline $2-4$ weeks & $8(8.2)$ & - & - \\
\hline $1-3$ months & $32(32.7)$ & - & - \\
\hline$>3$ months & $14(14.3)$ & - & - \\
\hline Adherent to ART & - & $57(80.3)$ & - \\
\hline $\begin{array}{l}\text { Time from HIV diagnosis } \\
\text { to treatment (days) }\end{array}$ & - & $56(1-17)$ & - \\
\hline
\end{tabular}

ART - antiretroviral treatment, MSM - men who have sex with men 
Table 2. First-line antiretroviral treatment regimens

\begin{tabular}{l|c}
\hline ART first-line regimens & $n(\%)$ \\
\hline TDF/FTC + EFV & $34(47.9)$ \\
\hline ZDV + 3TC + EFV & $27(38.0)$ \\
\hline $\mathrm{LPV} / \mathrm{r}+\mathrm{TDF}+\mathrm{FTC}$ & $2(2.8)$ \\
\hline $\mathrm{LPV} / \mathrm{r}+\mathrm{ZDV}+3 \mathrm{TC}$ & $2(2.8)$ \\
\hline $\mathrm{TDF} / \mathrm{FTC}+\mathrm{ATV} / \mathrm{r}$ & $1(1.4)$ \\
\hline $\mathrm{DTG}+\mathrm{ABC}+3 \mathrm{TC}$ & $1(1.4)$ \\
\hline
\end{tabular}

$3 T C$ - lamivudine, $A B C$ - abacavir, $A R T$ - antiretroviral treatment, ATV/r - atazanavir/ritonavir, DTG - dolutegravir, EFV - efavirenz,

FTC - emtricitabine, LPV/r-lopinavir/ritonavir, TDF-tenofovir disoproxil fumarate, $Z D V$-zidovudine

Table 3. Cascade of care in 2016

\begin{tabular}{l|c|c|c}
\hline Characteristics & Number & Percentage & $\begin{array}{c}90-90-90 \\
\text { projection }\end{array}$ \\
\hline $\begin{array}{l}\text { HIV diagnoses } \\
\text { (year 2016) }\end{array}$ & 127 & - & - \\
\hline Access in care & 100 & 78.7 & 114 \\
\hline $\begin{array}{l}\text { Received ARV } \\
\text { therapy }\end{array}$ & 71 & 71 & 102 \\
\hline $\begin{array}{l}\text { Periodic viral load } \\
\text { monitoring }\end{array}$ & 25 & 25 & - \\
\hline $\begin{array}{l}\text { Successful } \\
\text { suppression }\end{array}$ & 14 & 56 & 92 \\
\hline
\end{tabular}

ARV-antiretroviral

ed a growing epidemic in Eastern Europe, where Albania and Romania stood out as the countries with the highest incidence of new diagnoses [12]. Out of the 127 diagnosed cases, only $78.7 \%$ was enrolled in follow-up care, which shows that a link to care in Albania is much lower than the UNAIDS target of $90 \%$. Although the referral system in Albania works well after an initial diagnosis, the reasons for this low-rate linkage to care remains unknown for this study and require further investigation. On the other hand, among those linked to care, the median time from diagnosis to accessing care was quite short (19 days), with $86 \%$ in care within 30 days. While such a high proportion of entering care by the first month is encouraging, it also reflects a high proportion of inpatient hospital diagnosis.

2016 global estimates show that $86 \%$ of HIV-infected individuals know their status, and 78\% with a known diagnosis are on ART, with suppression achieved in $82 \%$ of those treated $[2,3]$. However, corresponding rates are much lower for Albania, with only $71 \%$ of patients initiating ART, viral load availability for only $35 \%$, and suppression detection in barely $56 \%$, which gives an overall rate of around $20 \%$ of virally suppressed patients out of 71 cases initiating ART.

North America and Western Europe reported the highest achieved rate of suppression and access to therapy ( $84 \%$ and $91 \%$, respectively), and admission to ART has increased sig- nificantly in sub-Saharan Africa, where over $80 \%$ of known HIV cases receive the treatment. Surprisingly, in 2016, only $45 \%$ of newly-diagnosed HIV cases in Eastern Europe and Central Asia initiate ART, which is mostly related to guidelines that still suggest a CD4+ T cell count threshold for ART initiation despite changes in major guidelines $[2,3,36]$. Late inpatient diagnosis remains the most common mode to diagnose HIV infection, and this study suggests a very highrate of late presenters (67\%) in Albania. Supported by a high number of hospital-based diagnoses (67\%), these findings reflect both a low HIV testing rate and a substantial disease burden in the general population. Such findings should be considered a significant disparity of our cascade of care, which also lacks evaluations on the size of undiagnosed population in Albania [13, 14].

HIV-related stigma is a recognized barrier to voluntary counseling and testing (VCT), which is one of the cornerstones of early diagnosis and a potentially effective intervention to prevent transmission in the population. Efforts to promote VCT and to minimize stigma require awareness campaigns [15-19], but despite efforts in Albania, information appears to be unevenly spread across the country. Campaigns, which mostly concentrate in major urban centers, are based on sex education in schools. A demographic health survey study in 2008-2009 indicated that many Albanian adults lacked knowledge on the HIV transmission modes [20-23].

Many factors have an impact on adherence to care among HIV-infected individuals, who need to comprehend their diagnosis. Patients should be provided with a detailed counseling on the importance of understanding the disease and long-term benefits of regular intake of medication. One study demonstrated an increased presence of depression and anxiety in patients diagnosed with HIV in Albania (62.3\% and $82.3 \%$, respectively) [24], with significantly higher rates than in general population [25-27]. These issues may directly influence the adherence of patients to care, specifically to ART, and require psychological counseling to improve self-reported adherence [28, 29].

In Albania, HIV treatment and healthcare services have been available since mid-2004, but only in the inpatient and outpatient clinics at Tirana University Hospital (TUH) and the HIV ambulatory clinic located within the hospital. Asymptomatic patients may be reluctant to present or receive care in a clinic linked to a hospital center due to high level of HIV-related stigma. Other factors associated with loss to follow-up include financial and practical difficulties in attending healthcare facilities due to the centralized healthcare system; no other options of care exist for newly diagnosed patients who do not attend healthcare services [30].

In the present study, antiretroviral treatment was initiated within a median time of 56 days from diagnosis in $71 \%$ of the patients. There are many limitations for universal access to ART in Albania. Although the most recent WHO and European AIDS Clinical Society (EACS) HIV treatment guidelines recommend the initiation of treatment in all HIV diagnoses regardless of the CD4+ T cell count, based on the results of the START trial [32-35], the previous thresh- 
old of $<500$ cells as well as clinical criteria still continue to be widely used in Albania to guide decision-making about initiation of ART [36]. Besides, latest ARVs with higher efficacy and fewer side effects are not currently available in Albania, and the lack of therapeutic options restricts an adequate adaptation of regimens to avoid comorbidities. A frequent shortage of ARVs is another critical barrier for access to ART and achieving viral suppression.

All treatment guidelines emphasize routine laboratory and clinical monitoring to assess response to ART and its potential side effects. It is recommended that all patients have their first CD4+T cell counts measured within two weeks of HIV diagnosis [31]. Although CD4+ T cell numbers were recorded for $98 \%$ of the patients entering follow-up care in the present study, less than half had their measurements performed within this timeframe. Viral load should be routinely measured at the time of diagnosis and repeatedly every 3-6 months after initiation of therapy, and at least every 6-12 months after complete suppression $[33,35]$. A considerable number of patients in this study could not obtain viral load assessments directly due to shortages of kits, which is yet another major gap in the HIV treatment and care cascade in Albania.

Drug resistance monitoring is not available in Albania. While the WHO does not recommend drug resistance testing in countries with limited resources, guidelines indicate that drug resistance testing should be used in cases with virologic failure to make decisions for transferring to second line regimens [41]. Therefore, the absence of viral load information in this study has clinical consequences regarding ART regimen changes instead being based upon clinical indications and drug availability.

\section{Conclusions}

The results of this study should be carefully interpreted, considering the fact that data represented the HIV treatment and care cascade of only one year and not a longer period. However, it shows that a large proportion of people living with HIV were lost at each step of the cascade in Albania. This paper highlights the importance of instituting and scaling up effective interventions at every step of the cascade in order to get closer to achieving the UNAIDS 90-90-90 target. The efforts in Albania should be focused on scaling up HIV testing among most at risk populations as well as provider-initiated testing, promoting adherence to ART, improving delivery and procurement of ARV drugs and test kits as well as improving access to better ART regimens and proper monitoring of therapy.

\section{Conflict of interest}

The authors declare no conflict of interest with respect to the research, authorship, and/or publication of this article.

\section{References}

1. Greene W. A history of AIDS: looking back to see ahead. Eur J Immunol 2007; 37: S94-S102.
2. Global HIV \& AIDS statistics - 2018 fact sheet. Available at: https:// www.unaids.org/en/resources/fact-sheet/ (Accessed: May 2019).

3. UNAIDS. 90-90-90: an ambitious treatment target to help end the AIDS epidemic. Geneva: UNAIDS; 2014. Available at: https://www. unaids.org/en/resources/documents/2017/90-90-90 (Accessed: August 2019).

4. Gardner EM, McLees MP, Steiner JF, Del Rio C, Burman WJ. The spectrum of engagement in HIV care and its Relevance to test-and-treat strategies for prevention of HIV infection. Clin Infect Dis 2011; 52: 793-800.

5. McNairy ML, Lamb MR, Abrams EJ, et al. Use of a comprehensive HIV care cascade for evaluating HIV program performance: findings from 4 sub-Saharan African countries. J Acquir Immune Defic Syndr 2015; 70: E44-51.

6. Levi J, Raymond A, Pozniak A, Vernazza P, Kohler P, Hill A. Can the UNAIDS 90-90-90 target be achieved? A systematic analysis of national HIV treatment cascades. BMJ Global Health 2016; 1: e000010.

7. Ministry of Health. The National Strategy of Prevention and Control of HIV/AIDS in Albania 2010-2015. Tirane: Ministry of Health; 2019. Available at: http://ccm-albania.al/wp-content/ uploads/2014/10/Strategjia-Kombetare-per-Parandalimin-dhe -Kontrollin-e-HIVAIDS-ne-Shqiperi-2010-2015.pdf.

8. HIV in Albania: an epidemiological review - September 2014. Available at: http://www. euro.who.int/_data/assets/pdf_file/0006/ 270096/HIV-in-Albania-an-Epidemiological-Review-Final.pdf.

9. National Center for Infectious Diseases Division of HIV/AIDS; Castro KG, Ward JW, Slutsker L, et al. 1993 revised classification system for HIV infection and expanded surveillance case definition for AIDS among adolescents and adults. MMWR Recomm Rep 1992; 41: 1-19.

10. Antinori A, Coenen T, Costagiola D, et al. Late presentation of HIV infection: a consensus definition. HIV Med 2011; 12: 61-64.

11. WHO. 2015. Antiretroviral therapy (ARV) coverage. [ONLINE] Available at: http://www.who.int/healthinfo/indicators/2015 (Accessed: 1.05.2018).

12. Gökengin D, Oprea C, Uysal S, Begovac J. The growing HIV epidemic in Central Europe: a neglected issue? J Virus Erad 2016; 2: 156-161.

13. Late presenters working group in COHERE in EuroCoord; Amanda Mocroft 1, Jens Lundgren, Andrea Antinori, et al. Late presentation for HIV care across Europe: update from the Collaboration of Observational HIV Epidemiological Research Europe (COHERE) study, 2010 to 2013. Euro Surveill 2015; 20.

14. Castilla J, Sobrino P, De La Fuente L, et al. Late diagnosis of HIV infection in the era of highly active antiretroviral therapy: consequences for AIDS incidence. AIDS 2002; 16: 1945-1951.

15. Turan B, Hatcher AM, Weiser SD, et al. Framing mechanisms linking HIV-related stigma, adherence to treatment, and health outcomes. Am J Public Health 2017; 107: 863-869.

16. Kalichman SC, Simbayi LC. HIV testing attitudes, AIDS stigma, and voluntary HIV counselling and testing in a black township in Cape Town, South Africa. Sex Transm Infect 2003; 79: 442-447.

17. Rintamaki LS, Davis TC, Skripkauskas S, Bennett CL, Wolf MS. Social stigma concerns and HIV medication adherence. AIDS Patient Care STDS 2006; 20: 359-368.

18. Thapa S, Hannes K, Cargo M, et al. Effect of stigma reduction intervention strategies on HIV test uptake in low- and middle-income countries: a realist review protocol. Syst Rev 2015; 4: 142.

19. Gesesew HA, Tesfay Gebremedhin A, Demissie TD, et al. Significant association between perceived HIV related stigma and late presentation for HIV/AIDS care in low and middle-income countries: a systematic review and meta-analysis. PLoS One 2017; 12: e0173928.

20. Bozicevic I, Brown A, Delpech V, Dvoriak S. HIV in Albania: an epidemiological review. September 2014. Available at: http:// www.euro.who.int/__data/assets/pdf_file/0006/270096/HIV- 
in-Albania-an-Epidemiological-Review-Final.pdf?ua=1 (Accessed: August 2019).

21. Bino S, Rjepaj K, Harxhi A, et al. Albania Behavioral and Biological Surveillance Study Report. May 2006. Available at: http://ishp. gov.al/docs/DESiSH/drogat/Albania_Bio\%20BSS\%202006\%20Report_ENG\%20-\%20doc\%209.pdf.

22. Roshi E, Bino S, Burazeri G, et al. Albania Biological and Behavioural Surveillance Study Final Report. 2013. Available at: https://www.academia.edu/23029301/Behavioural_and_Biological_Surveillance_Study_Albania_2013_JOINT_UNITED_NATIONS_PROGRAMME_ON_HIV_AIDS.

23. Albania Demographic and Health Survey 2008-2009. Institute of Statistics, Institute of Public Health, ICF Macro, 2010. Available at: https://dhsprogram.com/pubs/pdf/FR230/FR230.pdf (Accessed: August 2019).

24. Morrison SD, Banushi VH, Sarnquist C, et al. Levels of self-reported depression and anxiety among HIV-positive patients in Albania: a cross-sectional study. Croatian Medical Journal 2011; 52: 622-627.

25. Rabkin JG. HIV and depression: 2008 review and update. Curr HIV/AIDS Rep 2008; 5: 163-171.

26. Stober DR, Schwartz JA, McDaniel JS, Abrams RF. Depression and HIV disease: prevalence, correlates, and treatment. Psychiatr Ann 1997; 27: 372-377.

27. Remien RH, Mellins CA. Long-term psychosocial challenges for people living with HIV: let's not forget the individual in our global response to the pandemic. AIDS 2007; 21 (Suppl 5): S55-63.

28. Collins PY, Holman AR, Freeman MC, Patel V. What is the relevance of mental health to HIV/AIDS care and treatment programs in developing countries? A systematic review. AIDS 2006; 20: 15711582.

29. Stout BD, Leon MP, Niccolai LM. Nonadherence to antiretroviral therapy in HIV-positive patients in Costa Rica. AIDS Patient Care STDS 2004; 18: 297-304.

30. Yehia BR, Stewart L, Momplaisir F, et al. Barriers and facilitators to patient retention in HIV care. BMC Infect Dis 2015; 15: 246.

31. Helbert M, Breuer J. Monitoring patients with HIV disease. J Clin Pathol 2000; 53: 266-273.

32. INSIGHT START Study Group, Lundgren JD, Babiker AG, et al. Initiation of antiretroviral therapy in early asymptomatic HIV infection. N Engl J Med 2015; 373: 795-807.

33. World Health Organization. Guideline on when to start antiretroviral therapy and on pre-exposure prophylaxis for HIV. Geneva: World Health Organization; 2015. Available at: https://www.who.int/hiv/ pub/guidelines/earlyrelease-arv/en/ (Accessed: August 2019).

34. Ryom L, Boesecke C, Gisler V et al. Essentials from the $2015 \mathrm{Eu}$ ropean AIDS Clinical Society (EACS) guidelines for the treatment of adult HIV-positive persons. HIV Med 2016; 17: 83-88.

35. European AIDS Clinical Society Guidelines. Version 9.1. (October 2018) Available at: http://www.eacsociety.org/files/2018_guidelines -9.1-english.pdf (Accessed: August 2019).

36. Gokengin D, Oprea C, Begovac J, et al. HIV care in Central and Eastern Europe: how close are we to the target? Int J Infect Dis 2018; 70: 121-130.

37. Mills EJ, Nachega JB, Buchan I, et al. Adherence to antiretroviral therapy in Sub-Saharan Africa and North America: a meta-analysis. JAMA 2006; 296: 679-690.

38. Ye Ma, Zhihui Dou, Wei Guo, et al. The human immunodeficiency virus care continuum in China: 1985-2015. Clin Infect Dis 2018; 66: 833-839.

39. Kowalska JD, Aebi-Popp K, Loutfy M, et al. Promoting high standards of care for women living with HIV: position statement from the Women Against Viruses in Europe Working Group. HIV Med 2017; 19: 167-173.

40. Kaplan JE, Hamm TE, Forhan S, et al. The impact of HIV care and support interventions on key outcomes in low and middle-income countries: a literature review. Introduction. J Acquir Immune Defic Syndr 2015; 68 (Suppl 3): S253-S256.

41. World Health Organization Consolidated guidelines on the use of antiretroviral drugs for treating and preventing HIV infection: recommendations for a public health approach June 2013. Available at: https://www.who.int/hiv/pub/guidelines/arv2013/en/ (Accessed: August 2019). 